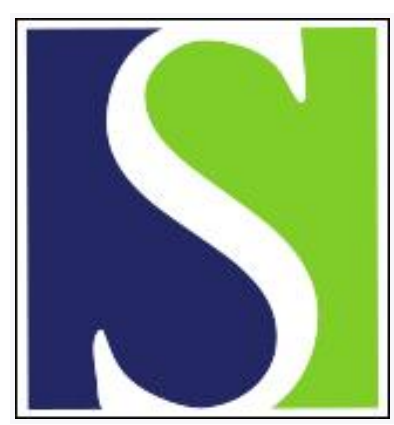

Scand J Work Environ Health 1984;10(1):57-58

https://doi.org/10.5271/sjweh.2362

Issue date: Feb 1984

Familial aggregation of symptoms of farmer's lung.

by Terho EO, Heinonen OP, Mantyjarvi RA, Vohlonen I

This article in PubMed: www.ncbi.nlm.nih.gov/pubmed/6740278

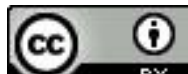




\title{
Familial aggregation of symptoms of farmer's lung
}

\author{
by Erkki O Terho, MD, ${ }^{1}$ Olli P Heinonen, MD, DSc, ${ }^{2}$ Rauno A Mäntyjärvi, MD, ${ }^{3}$ \\ Ilkka Vohlonen, $\mathrm{PhD}^{4}$
}

\begin{abstract}
TERHO EO, HEINONEN OP, MÄNTYJÄRVI RA, VOHLONEN I. Familial aggregation of symptoms of farmer's lung. Scand $j$ work environ health 10 (1984) 57-58. Not all farmers exposed to moldy plant materials develop farmer's lung. With the use of a postal questionnaire the occurrence of symptoms suggestive of farmer's lung was studied among the immediate relatives of 37 patients with clinically established farmer's lung, among the 36 immediate relatives of the patients' spouses, and among 50 unrelated persons (spouses of relatives). Symptoms of farmer's lung had occurred about twice as frequently among the relatives of farmer's lung patients as among the subjects in the other study groups. The results, supported by findings from earlier studies, imply that genetic factors may be involved in the pathogenesis of farmer's lung.
\end{abstract}

Key terms: extrinsic allergic alveolitis, genetics, hypersensitivity.

Farmer's lung, a common type of extrinsic allergic alveolitis, results from repeated exposure to moldy hay or other moldy plant material. However not all exposed farmers develop the disease, even if they have circulating precipitins to the of fending antigens. Genetic factors might influence predisposition to the disease, but so far such factors have not been elucidated (4). Some reports of a familial occurrence of extrinsic allergic alveolitis have been published $(1,5)$. Within each reported family, the diseased persons were exposed to the antigens of the same environment. The present study reports an increased occurrence of the symptoms typical of farmer's lung among the relatives of patients with diagnosed cases of the disease, irrespective of whether the relatives worked on the same farm as the patients or on a different farm.

\section{Subjects and methods}

Thirty-seven patients with clinically confirmed farmer's lung, the diagnostic criteria for which have been described recently elsewhere (4), and their spouses were asked for the names, dates of birth, occupations, and addresses of their siblings and for permission to contact them. The sibling who was the same sex, if possible, and roughly the same age as the rela-

1 Department of Pulmonary Diseases, Kuopio University Central Hospital, Kuopio, Finland.

2 National Public Health Institute, Helsinki, Finland.

3 Department of Clinical Microbiology, University of Kuopio, Kuopio, Finland.

+ Research Institute for Social Security, Social Insurance Institution of Finland, Helsinki, Finland.

Reprint requests to: Dr EO Terho, SF-71880 Tarinaharju, Finland. tive in question (ie, patient or patient's spouse) was selected for inclusion in the study. The spouse of the chosen sibling was also included. Preference was given to siblings in farming who lived on a farm in the same geographic region as the patient.

Parents and all the siblings of the patients or their spouses on the same farms as the patients were also included. Thus the material consisted of 44 immediate relatives of the farmer's lung patients, 36 immediate relatives of the patient's spouses, and 50 unrelated persons, ie, all of the spouses of the 80 relatives. The proportions of persons in farming were roughly the same in each study group (table 1).

Information on the occurrence of symptoms suggestive of farmer's lung during the last five years and other data were obtained by postal questionnaire. The subject was considered to have had symptoms of farmer's lung if he or she had experienced cough, shortness of breath, or fever, possibly with aches and pains, after some hours of having handled moldy hay or other moldy material.

In order to study the specificity of the findings for farmer's lung, we selected asthma and chronic bronchitis for comparison. Symptoms of asthma were considered to be present if the subject had ever experienced attacks of shortness of breath with wheezing at rest and the breathing had been normal between the attacks. Symptoms of chronic bronchitis were considered to be present if the subject brought up phlegm on most days for as much as three months a year and this phenomenon had occurred during at least two consecutive years.

Each subject was classified into only one of the four hierarchical categories, ie, farmer's lung, asthma, chronic bronchitis, or healthy. In addition a serum sample was obtained from each subject in the local health center. 
Table 1. Prevalences of symptoms of farmer's lung and of asthma or chronic bronchitis in the study groups.

\begin{tabular}{|c|c|c|c|c|c|c|}
\hline \multirow[t]{2}{*}{ Study group } & \multicolumn{2}{|c|}{$\begin{array}{l}\text { Occupied } \\
\text { in farming }\end{array}$} & \multicolumn{2}{|c|}{$\begin{array}{l}\text { Symptoms of } \\
\text { farmer's lung }\end{array}$} & \multicolumn{2}{|c|}{$\begin{array}{l}\text { Symptoms of asthma } \\
\text { or chronic bronchitis }\end{array}$} \\
\hline & $N$ & $\%$ & $N$ & $\%$ & $\mathrm{~N}$ & $\%$ \\
\hline Relatives of patients with farmer's lung $(N=44)$ & $26^{a}$ & 59 & 9 & 20 & 5 & 11 \\
\hline Relatives of patients' spouses $(N=36)$ & 27 & 75 & 4 & 11 & 4 & 11 \\
\hline Spouses of the relatives $(N=50)$ & 27 & 54 & 5 & 10 & 6 & 12 \\
\hline
\end{tabular}

a One part-time farmer.

\section{Results}

The results are shown in table 1. Symptoms of farmer's lung occurred about twice as frequently among the relatives of patients with farmer's lung as among the subjects in the other study groups, whereas the prevalence of the symptoms of asthma or chronic bronchitis did not differ between these groups. The difference in the prevalence of symptoms of farmer's lung remained when the analysis was restricted to the siblings in farming and their spouses. About $40 \%$ (8 of 19) of the patients' siblings, irrespective of whether they worked on the same farm as the patient or on a different one, had suffered from symptoms of farmer's lung, but only $14 \%$ (3 of 21) of the siblings of the patients' spouses and $19 \%$ ( 5 of 27) of the spouses of the subjects in each sibling group had suffered from symptoms of farmer's lung. When the latter two groups, with similar rates of symptoms of farmer's lung, were combined, the difference between the patients' siblings and persons who were not the patients' relatives was statistically significant $(p<0.05$ ), but again the analysis was based on small numbers. More-detailed analyses confirmed that the difference in the prevalence of symptoms of farmer's lung was not due to differences between the study groups with respect to age, sex, smoking habits, atopy, or work in cowsheds.

\section{Discussion}

The results suggest that genetic factors may be important in the development of farmer's lung. Due to the small size of the material, a possibility remains, however, that the differences observed may have occurred by chance. Furthermore, with this kind of study design, there may be a bias due to differences in the recall of symptoms. Relatives and family members of a patient with farmer's lung may recall symptoms of the disease more easily than others. In fact even the lowest prevalence of symptoms of farmer's lung in this material was more than four times as large as the prevalence of farmer's lung reported earlier in a community survey in the same geographic region (2). The criteria for farmer's lung in that sîdy were, however, different. We deliberately chose less rigorous but specific criteria, with respect to the mold exposure, to make sure that possible differences in the occurrence of even the slightest symptoms would be detected. In addition, even the subjects in the nonrelative study groups might be more aware of symptoms of farmer's lung than the general population, and they thus may have noticed and recalled the symptoms better. What is more important, the occurrence of such a phenomenon would make the comparison of the study groups more valid.

An analysis of the titers of class-specific immunoglobulin $\mathrm{G}$ antibodies against molds in the sera of the subjects of the present study yielded analogous, statistically significant differences between the study groups (unpublished data). As was the case with the prevalence of symptoms of farmer's lung, the differences were not due to differences between the study groups with respect to age, sex, smoking habits, atopy, or work in cowsheds. Our previous studies showed that some antigenic determinants were much more often found on the B cells of farmer's lung patients than on the corresponding cells of controls (3). Together with these findings, earlier reports on the familial occurrence of extrinsic allergic alveolitis $(1,5)$ also imply that genetic factors may be involved.

Further studies to confirm the findings seem necessary. The findings, if confirmed, would offer one way to select the population at risk for intensive health education regarding the prevention for occupational extrinsic allergic alveolitis.

\section{Acknowledgments}

The study has been supported financially by the Academy of Finland.

\section{References}

1. Allen DH, Basten A, Woolcock AJ. Familial hypersensitivity pneumonitis. Am j med 59 (1975) 505-515.

2. Katila M-L. Respiratory disease in a farming population: A sero-epidemiological survey of farmer's lung and chronic nonspecific lung disease among dairy farmers in Finland. University of Kuopio, Kuopio 1979. (Doctoral thesis).

3. Koskimies S, Terho EO, Heinonen OP, Mäntyjärvi R. Antigenic determinants on $B$ cells of farmer's lung patients. Eur j respir dis 63 (1982) 363-366.

4. Terho EO. Extrinsic allergic alveolitis - The state of the art. Eur j respir dis 63 (1982): suppl 124, 10-26.

5. Terry G, Murray K. Familial farmer's lung. Lancet 1 (1974) 1022. (A letter to the editor).

Received for publication: 14 September 1983 